\title{
Fifth-Power Altitude Dependence of Particle Precipitation at The Minimum Geomagnetic Field Position
}

\author{
M. M. Adel ${ }^{1}$ \\ Department of Chemistry \& Physics, University of Arkansas at Pine Bluff, Pine Bluff, AR 71601, USA
}

Abstract: The fifth power altitude dependence of magnetospheric particle precipitation near the geomagnetic equator in the altitude range of 160 to $300 \mathrm{~km}$ during moderate geomagnetic conditions has been explained. In the atmosphere, the observed altitude dependence of proton flux can be due to a number of factors such as (i) source attenuation, (ii) charge exchange loss of protons, (iii) proton loss due to atmospheric ionization, and (iv) proton loss due to pitch angle diffusion in the loss cone. Each of these causes has been discussed to estimate the importance in the explanation of the observed proton flux variation with altitude

\section{INTRODUCTION}

Magnetospheric particle precipitation in the atmosphere has been studied since the seventies of the last century using particle telescopes on board satellites (Hovestadt et al., 1972; Moritz, 1972; Mizera and Blake, 1973; Scholer et al., 1975). A number of articles have reported the observation of the global peak flux profile, energy spectra, solar cycle variation and the instrument efficiency function for detection particles of different pitch angles by the ONR-602 experiment on board the S81-1 pallet mission (Miah et al., 1988; Miah et al., 1989; Miah, 1989; 1990; Miah, 1991a; Miah, 1991b; Miah, 1993; Miah, 1993b; Miah, 1994a; Miah, 1994b; Adel, 2008; Adel, 2012; Adel, 2013). In the altitude range of $160 \mathrm{~km}$ to about $300 \mathrm{~km}$ of observation during moderate geomagnetic conditions the flux of proton precipitation near the minimum geomagnetic field exhibit a variation of the fifth power of altitude (Fig. 1). In the atmosphere, the observed altitude dependence of proton flux can be due to several factors which are (i) source attenuation, (ii) charge exchange loss of protons, (iii) proton loss due to atmospheric ionization, and (iv) proton loss due to pitch angle diffusion in the loss cone. This article explores all these possible reasons that have contributed to the altitude variation.

\section{MATERIALS AND METHOD}

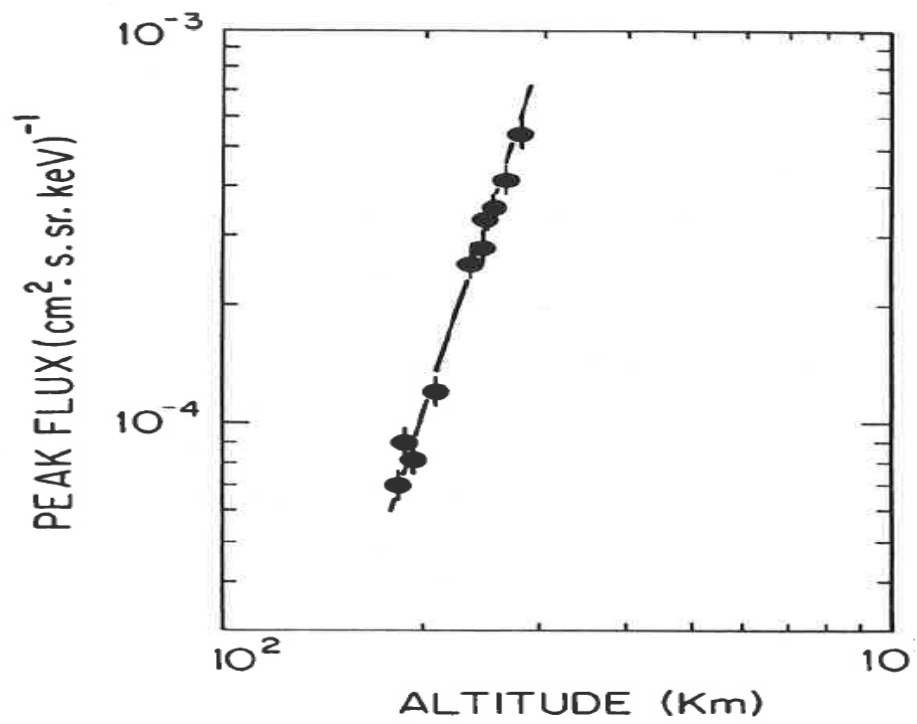

Fig 1. The fifth-power altitude dependence of the flux of protons precipitated from the magnetosphere at low equatorial altitude

\footnotetext{
${ }^{1}$ Corresponding Author: adelm@uapb.edu
} 


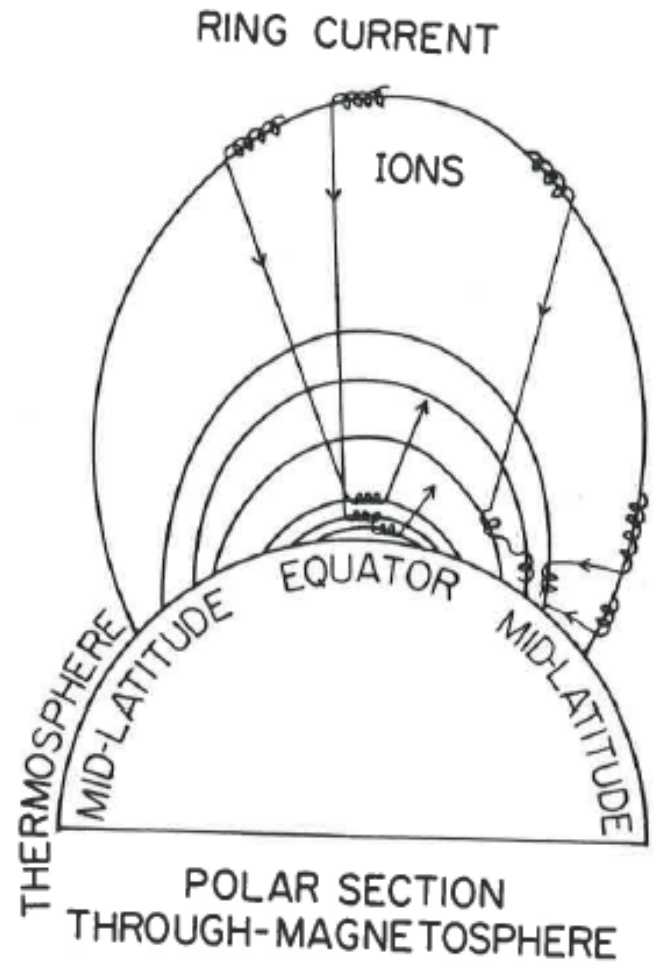

Fig2. Illustration of charge-exchange reaction

\subsection{Coulomb Interactions}

Another loss effect is though energy loss due to Coulomb interactions. But this is, comparatively, a much weaker process, as can be understood in these two examples: At $150 \mathrm{~km}$ a proton with an equatorial pitch angle of $\alpha_{\mathrm{e}}=90^{\circ}$ and $\mathrm{E}=1 \mathrm{MeV}$, has an electron capture lifetime of 0.4sec. and during this lifetime it loses $\sim 162 \mathrm{keV}$ and still remains as a proton for a long time. At $300 \mathrm{~km}$ which is the other extreme end (relative to the observational altitude range of 165-285 km), the same proton loses $2.64 \mathrm{keV}$ in its charge exchange lifetime of $34.3 \mathrm{secs}$. So, the energy loss process can be neglected unless some threshold energy value is specified below which the proton will be considered lost.

\subsection{Pitch Angle Diffusion}

The third loss effect is pitch angle diffusion. A proton during its charge exchange lifetime undergoes some scattering in pitch angle. If the pitch angle increases in the multiple Coulomb scattering process, the proton stays quasitrapped. If the pitch angle decreases, the proton has to mirror at a higher latitude $\lambda_{\mathrm{M}}$ i.e. lower atmosphere and be lost into the atmosphere.The relationship between the mirror latitude and the equatorial pitch angle is

$\sin ^{2} \alpha_{\mathrm{e}}=\operatorname{Cos}^{6} \lambda_{\mathrm{M}} /\left(1+3 \sin ^{2} \lambda_{\mathrm{M}}\right)^{0.5}$

or, approximately $\sin \alpha_{e}=\cos ^{4} \lambda_{M}$

Also, the loss cone size is an equatorial altitude dependent function. Usually, the loss cone size $\alpha_{\mathrm{o}}$ is defined with respect to the mirror point at $100 \mathrm{~km}$ which is taken as the effective edge of the atmosphere i. e.

$$
\alpha_{0}\left(r_{o}\right)=\sin ^{-1}\left[B_{e}\left(r_{o}\right) / B_{100}\right)^{0.5}
$$

All particle with $\alpha_{\mathrm{e}}$ between 0 and $\alpha_{\mathrm{o}}$ mirror at $\leq 100 \mathrm{~km}$ and are dumped into the atmosphere.

As shown in Table I below, the dipole field can trap particles of certain equatorial pitch angle range. $\mathrm{L}$ is the geocentric equatorial distance of a field line in units of the Earth's radius. The appropriate loss factor in this case is the ratio of the integral of the pitch angle distribution function within the pitch angle range at the altitude under consideration to the same integral between the pitch angle range at the normalization altitude (say $800 \mathrm{~km}$ ). Because the pitch angle distribution function is sharply peaked at $\alpha_{\mathrm{e}}=90^{\circ}$, this ratio is weakly dependent upon altitude. For 


\section{American Research Journal of Physics, Volume 1, Issue 1, 2015}

ISSN 2380-5714

the time being the inclusion of this ratio in the equation for the equilibrium situation is omitted. The ratio is important in combination with the instrument's sampling efficiency in pitch angle space.

Table1. Dipole Field-Trappable Particle with Equatorial Pitch Angles

\begin{tabular}{|c|c|c|}
\hline L & Equatorial Altitude $(\mathrm{km})$ & Equatorial Pitch Ange (deg.) \\
\hline 1.02354 & 150.00 & $\sim 80-1000$ \\
\hline 1.03139 & 200.00 & $\sim 76-104$ \\
\hline 1.03924 & 250.00 & $\sim 73-107$ \\
\hline 1.04708 & 300.00 & $\sim 70-110$ \\
\hline 1.05493 & 350.00 & $\sim 68-112$ \\
\hline 1.06278 & 400.00 & $\sim 66-114$ \\
\hline 1.07063 & 450.00 & $\sim 64-116$ \\
\hline 1.07848 & 500.00 & $\sim 62-118$ \\
\hline 1.08633 & 550.00 & $\sim 61-119$ \\
\hline 1.09418 & 600.00 & $\sim 59-121$ \\
\hline 1.10202 & 650.00 & $\sim 58-122$ \\
\hline 1.10987 & 700.00 & $\sim 57-123$ \\
\hline 1.11772 & 750.00 & $\sim 56-126$ \\
\hline 1.12557 & 800.00 & $\sim 54-126$ \\
\hline 1.13342 & 850.00 & $\sim 53-127$ \\
\hline 1.14126 & 900.00 & $\sim 51-129$ \\
\hline 1.14911 & 950.00 & $\sim 50-130$ \\
\hline 1.15696 & 1000.00 & $\sim 49-131$ \\
\hline
\end{tabular}

At any time $t$ and at any altitude $h$ the equation describing generation and loss of protons of $\alpha_{\mathrm{e}}=90^{\circ}$ can be written as Accumulation rate of proton flux $=$ generation rate of proton flux - loss rate of proton flux , i.e.

$$
\underline{d j}_{p} \frac{(E, h)}{d t}=v\left[\sum_{01}(h, E)\right] j_{H}(E, h)-v\left[\sum_{10}(h, E)\right] j_{p}(E, h)
$$

where $\mathrm{j}_{\mathrm{p}}(\mathrm{E}, \mathrm{h})$ is the differential proton flux $\left(\mathrm{cm}^{2}-\mathrm{s}-\mathrm{sr}-\mathrm{keV}\right)^{-1}$;

$\mathrm{j}_{\mathrm{h}}(\mathrm{E}, \mathrm{h})$ is the differential neutral hydrogen flux $\left(\mathrm{cm}^{2}-\mathrm{s}-\mathrm{sr}-\mathrm{keV}\right)^{-1}$;

$$
\sum_{01}(\mathrm{~h}, \mathrm{E})=\sum \mathrm{n}(\mathrm{E}, \mathrm{h})_{\mathrm{i}}\left(\sigma_{01}(\mathrm{E})\right)\left(\mathrm{cm}^{-1}\right)
$$

is the sum of the products of the atmospheric constituents and their electron stripping cross-sections for energetic neutral hydrogen

$$
\sum_{10}(\mathrm{~h}, \mathrm{E})=\sum \check{\mathrm{n}}(\mathrm{E}, \mathrm{h})_{\mathrm{i}}\left(\sigma_{10}(\mathrm{E})\right)_{\mathrm{i}}\left(\mathrm{cm}^{-1}\right)
$$

is the sum of the products of bounce average density of atmospheric constituents

(Fig. 3) and the electron capture cross sections for protons (Toburen et al., 1968); and $\mathrm{v}$ is the velocity of the energetic neutrals or of the energetic protons.

The lifetime against neutralization is defined as

$$
\tau_{\mathrm{CE}}\left(\mathrm{h}, \alpha_{\mathrm{e}}\right)==\left[\sum \check{\mathrm{n}}(\mathrm{E}, \mathrm{h})_{\mathrm{i}}\left(\sigma_{10}(\mathrm{E})\right)_{\mathrm{i}} \mathrm{v}\right]^{-1}
$$

is a strong function of proton energy and a weak function of pitch angle.

For an equilibrium condition, Eq. (4) yields

$$
\frac{\mathrm{J}_{\mathrm{H}}(\mathrm{E}, \mathrm{h}) \sum_{01}(\mathrm{~h}, \mathrm{E})}{\sum_{10}(\mathrm{~h}, \mathrm{E})}=\mathrm{j}_{\mathrm{p}}(\mathrm{E}, \mathrm{h})
$$




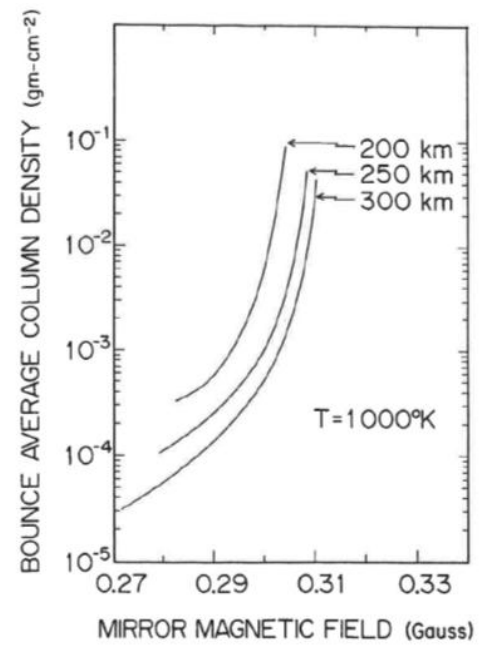

Fig3. Bounce average atmospheric column density vs mirror point magnetic fields for three different equatorial altitudes.

Fig. 4 illustrates the mechanism of charged particle trapping in the geomagnetic field. For equatorially mirroring particles of $\alpha_{e}=90^{\circ}, n_{i}$ is the same as $\breve{n}_{i}$ (cyclotron orbit average density was not calculated since cyclotron radius $<<$ density scale height), so, for these particles the ratio in Eq. (8) is effectively a function of energy through the ratios of electron capture to electron loss cross sections. Eq. (8) shows that any dependence of $\mathrm{j}_{\mathrm{p}}$ on altitude can be introduced through the altitude dependence of $\mathrm{j}_{\mathrm{H}}$.

To investigate the depletion of source neutrals as a function of both energy and altitude, the fraction of the surviving neutrals at any altitude was calculated. This fraction is given by

$$
\mathrm{W}_{\mathrm{AT}}(\mathrm{E}, \mathrm{h})=\mathrm{e}^{-\sum \mathrm{S}(\mathrm{h}) \sigma}{ }_{\mathrm{i} 01}(\mathrm{E})_{\mathrm{i}}
$$

where $\mathrm{S}(\mathrm{h}) \mathrm{i}$ is the column density of the ith atmospheric constituent, and the sum runs over all the atmospheric constituents. In a spherically symmetric atmosphere, at a given altitude in the equatorial plane, column densities (starting from $2500 \mathrm{~km}$ ) of individual gases in the zenith angle range $-90^{\circ} \leq{ }^{\theta} \geq 90^{\circ}$ (which takes care $\sim 30 \%$ of the equatorial part of the $\mathrm{L}$ shells in the range $2.5-3.5$ ) was calculated at intervals of $1^{\circ}$. The column densities were multiplied by the electron stripping cross sections of the individual gases, and the fraction in Eq. (9) is evaluated for the full angular range. The average value of $\mathrm{W}_{\mathrm{AT}}(\mathrm{E}, \mathrm{h})$ was then determined for the given equatorial altitude. The average fraction of remaining neutral hydrogen was also calculated as a function of energy, and $\mathrm{W}_{\mathrm{AT}}(\mathrm{E}, \mathrm{h})$ as a function of both energy and altitude as shown in Fig. 5. The figure shows 4 curves at specified energy values and then weighted average over the whole energy range based on an $\mathrm{E}^{-2.55}$ energy spectrum. The remaining proton fraction is normalized to 0.5 at $600 \mathrm{~km}$. A strong altitude gradient of the fraction of undepleted neutrals starting from approximately $400 \mathrm{~km}$ is indicated.

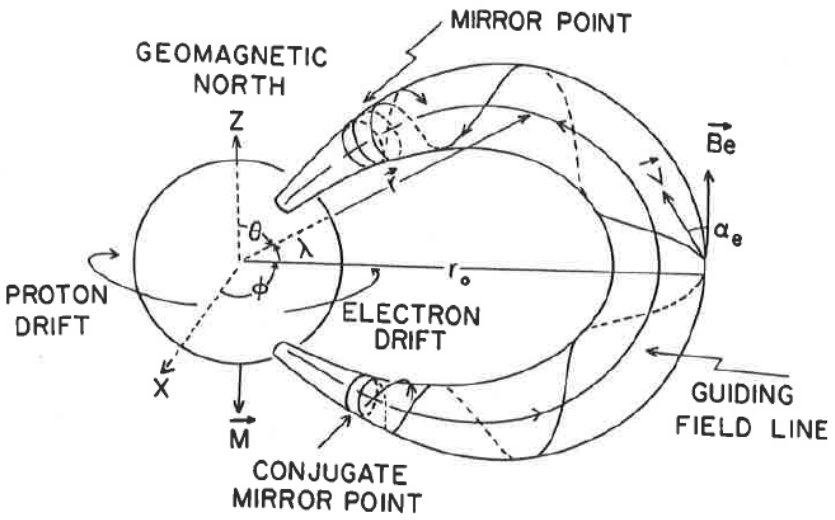

Fig4. Trapping mechanism of charged particles by performing cyclotron motion around magnetic field lines, bouncing back and forth between two mirror points, and drifting around the Earth. 


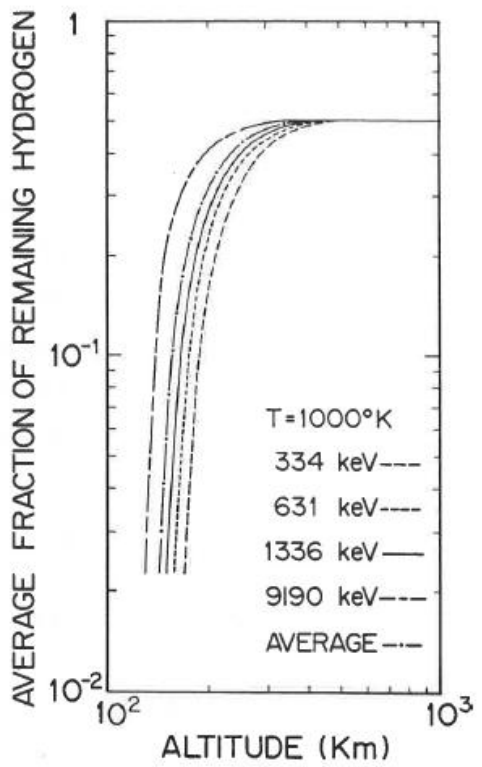

Fig5. Altitude vs average fraction of remaining neutrals at different energies

The undepleted neutrals will be converted to protons according to this relation

$$
\mathrm{j}_{\mathrm{P}}(\mathrm{E}, \mathrm{h})=\left[\sum_{01}(\mathrm{~h}, \mathrm{E}) / \sum_{10}(\mathrm{~h}, \mathrm{E})\right] \mathrm{j}_{\mathrm{H}}(\mathrm{h}, \mathrm{E})
$$

The surviving protons at any altitude as detected in the Phoenix-1 experiment, are then given by the product of the survival probability for ionization loss $\left(1-\mathrm{W}_{10}\right)$ which depends on the instrumental threshold, the sampling efficiency of the instrument in pitch angle space combined with the pitch angle distribution function, which is called loss cone effect $\mathrm{W}_{\mathrm{LC}}$, and $\mathrm{j}_{\mathrm{p}}(\mathrm{E}, \mathrm{h})$.

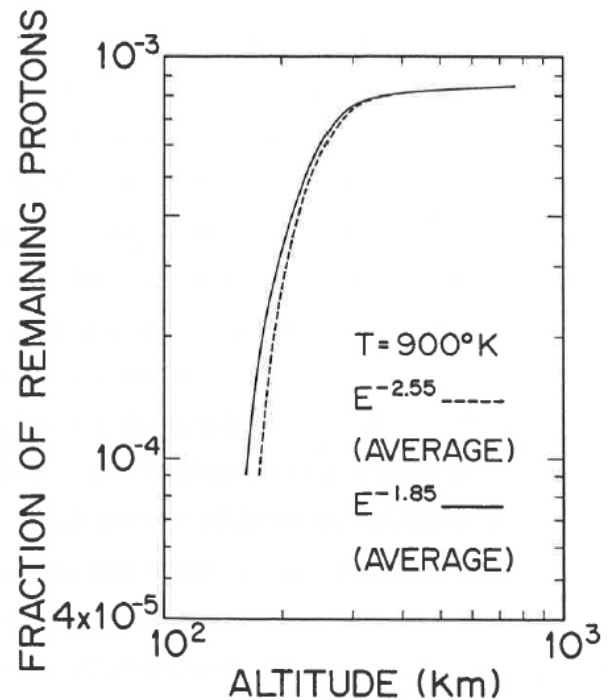

Fig6. Surviving protons vs. altitudes at two different spectral indices showing that the effect of altitude dependence is not significant if the spectral index is reduced from 2.55 to 1.85

\subsection{Proton survival from Ionization loss}

Ionization loss of protons occur through Coulomb excitation energy loss in the atmosphere. A quasi-trapped proton at any equatorial altitude loses some energy $\Delta \mathrm{E}$ in its lifetime in bouncing between two mirror points (Fig. 4). 


\section{American Research Journal of Physics, Volume 1, Issue 1, 2015}

ISSN 2380-5714

The spiral arc length traversed by a proton of equatorial distance $r_{\mathrm{o}}$ is given by Eqs.

$$
\mathrm{s}\left(\alpha_{\mathrm{e}}\right) \sim 1.38-0.32\left(\sin \alpha_{\mathrm{e}}+\sqrt{ }_{\sin } \alpha_{\mathrm{e}}\right)
$$

and

$$
\mathrm{dl}^{*}=\mathrm{dl} / \cos \alpha=\mathrm{r}_{\mathrm{o}} \mathrm{s}\left(\alpha_{\mathrm{e}}\right)
$$

Within $0 \leq \alpha_{\mathrm{e}} \leq \pi / 2$, the bounce period varies less than a factor of 2 . The spiral length $\mathrm{dl}^{*}$ and the field arc length $\mathrm{dl}$ and the local pitch angle $\alpha$ are related by Eqn. (12) which shows almost independence of dl* upon pitch angle.

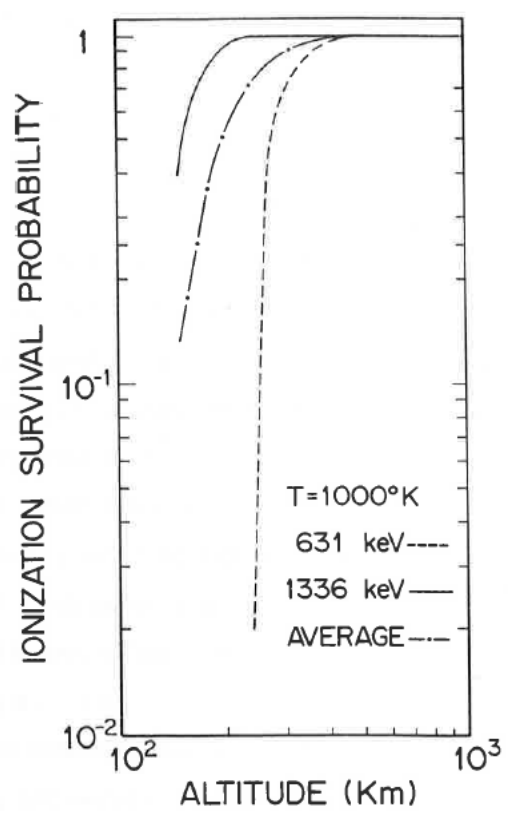

Fig7. Ionization survival probability vs altitude at $631 \mathrm{keV}, 1336 \mathrm{keV}$, and the average probability for the entire energy range

Multiplying the bounce average density corresponding to the given $\alpha_{e}$ and $r_{o}$, by the spiral arc length, we get the atmospheric column density experience by the proton. Energy loss of protons was calculated in a diatomic oxygen atmosphere, and, if the proton energy fell below $0.60 \mathrm{MeV}$, it was not detected. The ionization loss probability is defined as

$$
\mathrm{W}_{\mathrm{IO}}(\mathrm{E}, \mathrm{h})=\Delta \mathrm{E} /\left(\mathrm{E}-\mathrm{E}_{\mathrm{thrs}}\right)
$$

where $\mathrm{E}_{\text {thrs }}$ is the threshold $=600 \mathrm{keV}$. For a single particle, if $\mathrm{E}>\mathrm{E}_{\mathrm{thrs}}$, the particle will be detected. However, its detectability depends also upon the energy $\Delta \mathrm{E}$ it loses. If $\Delta \mathrm{E}$ is zero, the surviving probability is 1 . On the other hand, if $\Delta \mathrm{E}$ is such that the energy has been reduced to $\mathrm{E}_{\text {thrs }}$, the surviving probability vanishes. And $\Delta \mathrm{E}$ depends upon the proton pitch angle, proton energy, and the altitude. The characteristics of $\mathrm{W}_{\mathrm{IO}}(\mathrm{E}, \mathrm{h})$ has to be the following:

The higher the altitude, the lower the value of $\mathrm{W}_{\mathrm{IO}}(\mathrm{E}, \mathrm{h})$,

The higher the energy, the lower the $\mathrm{W}_{\mathrm{IO}}(\mathrm{E}, \mathrm{h})$, and

The higher the difference $\left|90^{\circ}-\alpha_{\mathrm{e}}\right|$, the higher the $\mathrm{W}_{\mathrm{IO}}(\mathrm{E}, \mathrm{h})$

The energy loss bears the signatures of these three effects. In a distribution of particles, $\mathrm{W}_{\mathrm{IO}}(\mathrm{E}, \mathrm{h})$ represents the loss probability of particles of energy greater than $600 \mathrm{keV}$. The corresponding ionization survival probability function is defined as

$$
1-\mathrm{W}_{\mathrm{IO}}(\mathrm{E}, \mathrm{h})=1-\frac{\Delta \mathrm{E}}{\mathrm{E}-\mathrm{E}_{\mathrm{thrs}}}
$$

Table II shows $\Delta \mathrm{E}$ as a function of $\mathrm{E}$ and $\alpha_{\mathrm{e}}$.Fig. 7 shows the ionization survival probability at $631 \mathrm{keV}, 1336 \mathrm{keV}$, and the average probability for the entire energy range. The probability function is normalized to unity at $600 \mathrm{~km}$. 
Below $150 \mathrm{~km}$, the probability function value is not shown. In the calculation, $\Delta \mathrm{E}$ represents the energy loss in a bounce path. Steep curves appear at low altitudes and energies.

Table2. Ionization Survival Probability

\begin{tabular}{|c|c|c|c|c|c|c|}
\hline $\mathrm{h}$ & E & $\alpha_{\mathrm{e}}$. & $\tau_{\mathrm{CE}}$ & $\#$ of & Drift & $\Delta \mathrm{E}$ \\
\hline (km) & $\underline{(\mathrm{keV})}$ & $(\mathrm{deg})$ & $(\mathrm{sec})$ & Bounces & $\underline{\text { Period }(\min )}$ & (keV/Bounce) \\
\hline \multirow{4}{*}{200} & \multirow[t]{2}{*}{631} & 90 & 0.764 & 0.431 & 40.59 & 104 \\
\hline & & 85.7 & 0.694 & 0.391 & 40.62 & 115 \\
\hline & \multirow[t]{2}{*}{1336} & 90 & 6.730 & 5.530 & 13.23 & 61.2 \\
\hline & & 85.7 & 6.120 & 5.020 & 13.24 & 67.5 \\
\hline \multirow{4}{*}{250} & \multirow[t]{2}{*}{631} & 90 & 2.810 & 1.580 & 40.28 & 28.2 \\
\hline & & 85.7 & 2.550 & 1.410 & 40.31 & 31.2 \\
\hline & \multirow[t]{2}{*}{1336} & 90 & 24.80 & 20.20 & 13.13 & 16.6 \\
\hline & & 85.7 & 22.40 & 18.30 & 13.14 & 18.4 \\
\hline \multirow{4}{*}{300} & \multirow[t]{2}{*}{631} & 90 & 8.350 & 4.650 & 39.98 & 9.50 \\
\hline & & 85.7 & 7.860 & 4.360 & 40.14 & 10.1 \\
\hline & \multirow[t]{2}{*}{133} & 90 & 73.70 & 59.60 & 13.03 & 5.60 \\
\hline & & 85.7 & 69.30 & 56.00 & 13.04 & 5.96 \\
\hline
\end{tabular}

\subsection{Loss Cone Effect}

So far we are dealing with $\alpha_{\mathrm{e}}=90^{\circ}$ particles at the equator, but we can extend the treatment to include particles of all other pitch angles. We can think of neutrals reaching other latitudes, and can similarly, as mentioned in the paragraph of Eq. (9), find their contribution at those latitudes. However, an easier way to include them is through a weighting factor $\mathrm{W}_{\mathrm{LC}}$ which takes care of the increased equatorial pitch angle ranges with increasing altitude and the instrument's efficiency to detect particles of different equatorial pitch angles. Table I shows the equatorial pitch angle ranges in different equatorial altitude ranges. With decreasing altitude, the magnetic field has decreasing capability of keeping particles trapped/quasi-trapped, since the size of the loss cone is a function of the equatorial altitude (Eq. (3). $\mathrm{W}_{\mathrm{LC}}$ is equal to the right hand side of Eq. (15.) (which is an integral of the product function of equatorial pitch angle distribution and the instrumental efficiency), with the appropriate limits of integration taken as a function of altitude, i.e.

$$
W_{L C}=\sum F\left(\alpha_{j}\right) f\left(\alpha_{j}\right) d \alpha
$$

where $F\left(\alpha_{j}\right)=\sin ^{13} \alpha_{\mathrm{j}}$ has been used as the pitch angle distribution function. The values of $\mathrm{W}_{\mathrm{LC}}$ are listed in Table IIII for the pitch angle ranges relevant to different altitudes

Table IIIW $\mathrm{LC}_{\mathrm{LC}}$ for Different Altitudes and Pitch Angle Ranges

\begin{tabular}{|c|c|c|}
\hline Altitude $(\mathrm{km})$ & Pitch angle Range $(\mathrm{deg})$ & $\mathrm{W}_{\mathrm{LC}}$ (Normalized at $\left.800 \mathrm{~km}\right)$ \\
\hline 175 & $90 \pm 12$ & 0.645 \\
\hline 200 & $90 \pm 14$ & 0.808 \\
\hline 250 & $90 \pm 17$ & 0.889 \\
\hline 300 & $90 \pm 20$ & 0.924 \\
\hline 350 & $90 \pm 22$ & 0.964 \\
\hline 400 & $90 \pm 24$ & 0.979 \\
\hline 450 & $90 \pm 26$ & 0.989 \\
\hline 500 & $90 \pm 28$ & 0.994 \\
\hline 600 & $90 \pm 31$ & 0.998 \\
\hline 800 & $90 \pm 36$ & 1.000 \\
\hline
\end{tabular}

$\mathrm{W}_{\mathrm{LC}}$ is not a strong function of altitude. In the observational altitude range it varies by a factor or $\sim 1.4$. At any altitude it depends on the pitch angle distribution and the instrumental efficiency. It does not depend on energy since we assume $f(\alpha)$ in Eqn. (15) is independent of energy. 


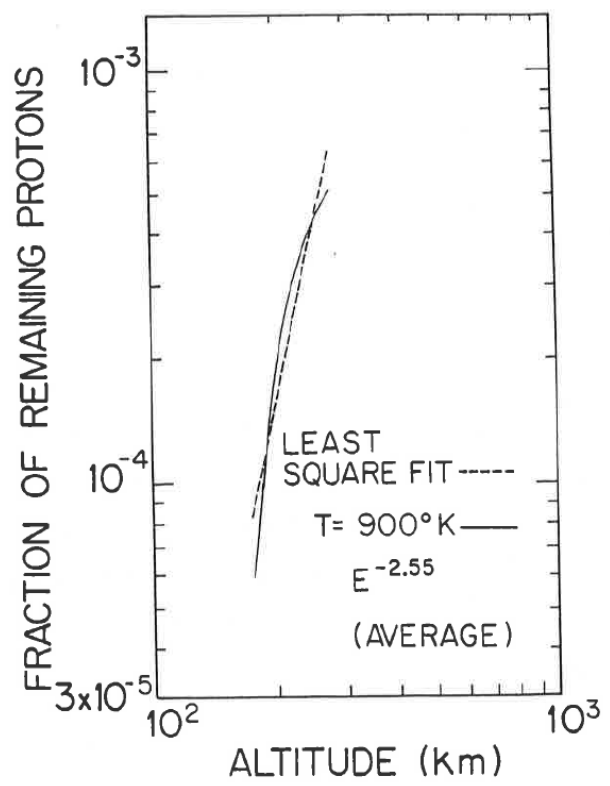

\section{RESULT AND DISCUSSION}

The final fraction of protons of energy $\mathrm{E}$ surviving at altitude $\mathrm{h}$ is given by

$$
\mathrm{f}_{\mathrm{p}}(\mathrm{E}, \mathrm{h})=\mathrm{W}_{\mathrm{LC}}\left(1-\mathrm{W}_{\mathrm{IO}}\right) \mathrm{W}_{\mathrm{AT}}
$$

We have done a least square fit to this function in the altitude range 175 to $275 \mathrm{~km}$. To get this function at any altitude, we multiplied the average of both $\left(1-\mathrm{W}_{\mathrm{IO}}\right)$ and $\mathrm{W}_{\mathrm{AT}}$ over the entire energy range of the instrument, weighted by $\mathrm{E}^{-2.55}$ spectra. The product function has been plotted in Fig. 8 as a function of altitude. To find the power law represented by the solid line within the observational altitude range for comparison with fifth power altitude dependence of flux, a least square fit was done. The dotted line represents the least square fit line. It has a slope of $4.56 \pm 0.26$. This explains closely the observed $5^{\text {th }}$ power altitude dependence of the measured proton flux in our observational altitude range. To evaluate $\mathrm{f}_{\mathrm{p}}(\mathrm{E}, \mathrm{h})$ we have used Jacchia atmosphere (1977) at $900^{\circ} \mathrm{K}$ which was the mean temperature for the local time of the Phoenix -1 observations.

Since we did not consider any secondary generation of protons in the model, the agreement between the observed and the model predicted slopes indicates that the primary proton flux will outnumber the secondary or higher order generation of proton flux, or in other words, secondary or higher order generation of protons will not have a significant effect upon the protons produced from the primary beam of incident neutrals.

The turnover of the altitude variation curve beyond $300 \mathrm{~km}$ also explains the altitude independence of the proton flux reported by Moritz (1972).

\section{CONCLUSION}

The charge exchange loss coupled with the loss cone effect can explain the fifth-power altitude variation of magnetospheric particle precipitation at low altitude near the geomagnetic equator.

\section{REFERENCES}

[1] Adel, M.M., 2008. A detector telescope's pitch angle sampling of magnetospheric particles. Earth, Planets Space, 60: 753-761.

[2] Adel, M. M., 2012. Absolute flux comparison of magnetospheric particles, Physics International., 3:1-8; DOI: 10.3844/pisp.2012.1.8; URL: http://thescipub.com/abstract/10.3844/pisp.2012.1.8

[3] Adel, M. M., 2013. Rotation matrix method for calculation of a detector telescope's response function, Projournal of Physical Science Research,Vol. 1(2), pp.14-30, September 2013; nline: http://www.projournals.org/PPSR 
[4] Cabera, J., M. Cyamukungu, P. Stauning, A. Leonov and P. Leleux et al., 2005. Fluxes of energetic protons and electrons measured on board the Oersted satellite. Ann. Geophys., 23: 2975-2982.

[5] Guzik, T.G, M. A. Miah, J. W. Mitchell, and J. P. Wefel, 1987. Low energy protons atthe equatorial zone, Journal of Geophysical Research, vol. 94, pp. 14-21

[6] Hovestadt, D., B. Hausler and M. Scholer, 1972. Observation of energetic particles at very low altitudes near the geomagnetic equator. Phys. Rev. Lett., 28: 1340-1344.

[7] Miah, M.A., 1988. Global Zones of Particle Precipitation. Ph. D. Thesis, Department of Physics and Astronomy, Louisiana State University, Baton Rouge.

[8] Miah, M. A., 1989. Observation of low energy particle precipitation at low altitude in the equatorial zone, Journal of Atmospheric and Terrestrial Physics, vol.51, pp.541-550

[9] Miah, M. A., 1990. Observation of $Z \geq 1$ particles below $300 \mathrm{~km}$ near the geomagnetic equator, Journal of Geomagnetism and Geoelectricity, vol. 43, pp. 461-472.

[10] Miah, M. A., 1991. Global proton peak flux profile in the equatorial zone, Indian Journal of Radio and Space Science, vol. 20, pp.12-24

[11] Miah, M. A., 1991. ONR-602 experiment to investigate particle precipitation near the equator, Journal of Geomagnetism and Geoelectricity, vol. 43, pp.445-454.

[12] Miah, M. A., J. W. Mitchell, and J. P. Wefel, 1989. Magnetospheric particle detection efficiency of a conical telescope, Nuclear Instrumentation and Methods in Physics Research, vol. A281, pp. 622-632

[13] Miah, M. A., 1993. Solar-induced variation of proton precipitation near the equator, Journal of Atmospheric and Terrestrial Physics, vol.55, no. 9, pp.1295-1301

[14] Miah, M. A., 1993. Solar cycle dependence of equatorial protons in the thermosphere, vol. 2, p. 721, in Hruska,

[15] Shea, Smart, and Heckman, eds., Proceedings of the Solar-TerrestrialPredictions - IV Workshop, Montreal, Canada

[16] Miah, M. A., 1994. Phoenix-1 observation of storm-time precipitation of ring current particles, UAPB Research Journal, vol.1, pp.45-54

[17] Miah, M. A., 1994. Significant variation of proton precipitation in equatorial thermosphere, Advances in Space research, vol.14, no. 9, pp.229-235

[18] Miah, M. A., 1994. EXOS-C project at UAPB, UAPB Research Journal, vol. 1, pp.17-25

[19] Miah, M.A., J.W. Mitchell and J.P. Wefel, 1989. Magnetospheric particle detection efficiency of a conical telescope. Nucl. Instr. Meth. Phys. Res., 281: 622-627. DOI: 10.1016/0168-9002(89)91499- X Phy. Intl. 3 (1): $1-8,20128$

[20] Miah, M.A., K. Nagata, T. Kohno, H. Murakami and A. Nakamoto et al., 1992. Spatial and temporal features of 0.64-35 MeV protons in the space station environment: EXOS-C observations, J. Geomagnetism Geoelec., 44: 591-610.

[21] Miah, M. A.. K. Nagata, T. Kohno, H. Murakami, A. Nakamoto, N. Hasebe, J. Kikuchi, and T. Doke, 1992. Spatial and temporal features of $0.64-35 \mathrm{MeV}$ protons in the Space Station environment: EXOS-C observations, Journal of Geomagnetism and Geoelectricity, vol. 44, pp. 9-20.

[22] Mizera, P.F. and J.B. Blake, 1973. Observations of ring current protons at low altitudes. J. Geophys. Res., 78: 1058-1062. DOI: 10.1029/JA078i007p01058

[23] Moritz, J., 1972. Energetic protons at low equatorial altitudes. Zeitschrift fur Geophysik, Band, 38: 701-717.

[24] Scholer, M., D. Hovestadt and G. Morfil, 1975. Energetic He+ ions from the radiation belt at low altitudes near the geomagnetic equator. J. Geophys. Res., 80: 80-85. DOI: 10.1029/JA080i001p00080

[25] Sullivan, J.D., 1971. Geometrical factor and directional response of single and multi-element particle telescopes. Nucl. Instruments Meth., 95: 5-11. DOI: 10.1016/0029-554X(71)90033-4

[26] Toburen, L. H., M. Y. Nakai, and R. A. Langley, 1968. Measurements of high energy charge-transfer crosssections for incident protons and atomic hydrogen in various gases, Physical Review, Vol. 171, No. 114. 
American Research Journal of Physics, Volume 1, Issue 1, 2015

ISSN 2380-5714

[27] Yusif, A.K., I.B. Bahari and M.S. Yasin, 2010. Identifications of the specific relations among physical parameters which use to quantify interaction effect of charged particles at low dose. Phys. Int., 1: 90-94. DOI: 10.3844/pisp.2010.94.98

[28] Wentworth, R. C., 1960. Lifetimes of geomagnetically trapped particles determined by Coulomb scattering, $\mathrm{Ph}$. D. Thesis, University of Maryland, p.112. 